\title{
Agro-Forest Management and Soil Degradation in Mediterranean Environments: Towards a Strategy for Sustainable Land Use in Vineyard and Olive Cropland
}

\author{
Maurizio Marchi ${ }^{1, *(D)}$, Carlotta Ferrara ${ }^{1}$, Rita Biasi ${ }^{2}$, Rosanna Salvia ${ }^{3}$ (D) and Luca Salvati ${ }^{1}$ \\ 1 Council for Agricultural Research and Economics (CREA), Research Centre for Forestry and Wood, \\ Viale S. Margherita 80, I-52100 Arezzo, Italy; carlotta.ferrara@gmail.com (C.F.); bayes00@yahoo.it (L.S.) \\ 2 Department for Innovation in Biological, Agro-Food and Forestry Systems (DIBAF), Tuscia University, \\ via San Camillo de Lellis, I-01100 Viterbo, Italy; biasi@unitus.it \\ 3 Department of Mathematics, Computer Science and Economics, University of Basilicata, \\ Via dell'Ateneo Lucano, I-85100 Potenza, Italy; rosanna.salvia@unibas.it \\ * Correspondence: maurizio.marchi@crea.gov.it; Tel.: +39-349-838-7082
}

Received: 13 June 2018; Accepted: 20 July 2018; Published: 22 July 2018

\begin{abstract}
Landscape fragmentation typical of the Mediterranean region is the result of long-term settlement history and continuous socioeconomic interactions among countries. In complex agro-ecosystems of the Mediterranean basin, formulation of practical guidelines aimed at counteract soil and land degradation, water depletion, rural area depopulation, and the loss of agricultural knowledge is imperative. Based on a multidisciplinary, integrated approach, the present contribution discusses the role of traditional agricultural systems in ecosystem services provision, considering together economic sustainability and the medium-term ecological benefits. A permanent monitoring of rural areas specialized in traditional crop production such as olive and vine may support optimal selection of cultivars finely adapted to a warm climate. A competitive agricultural system may consider human well-being, social equity, and conservation of natural resources, to ensure a high level of services for current and future generations. Recovery and conservation of agricultural resources provide positive externalities and social benefits at both local and regional levels. Understanding the multiple use and functions of tree crop landscapes will contribute to improve food security, land quality, and the provision of related ecosystem services.
\end{abstract}

Keywords: landscape; olive groves; vineyards; permanent environmental assessment; coastal area; Southern Europe

\section{Introduction}

Agricultural land and agro-forest ecosystems represent the main background of a landscape mosaic in which peri-urban areas are often included, and whose sustainable management will play a key role in habitat conservation all over Europe [1,2]. According to Corine Land Cover data (retrieved from https:/ /land.copernicus.eu/pan-european/corine-land-cover/clc-2012), agricultural land and forests currently represent $68 \%$ of the European territory (Figure 1). Traditional landscapes in the Mediterranean basin, considered the cradle of world civilization, are representative of long-term population dynamics; especially in southern Europe, local populations have managed natural resources (primarily cropland and forest) looking for a trade-off between exploitation and conservation through the ages [3-6]. Preserving natural land in Mediterranean ecosystems is a relevant challenge for decision-makers due to unique geophysical complexity, spatial variability, intrinsic socioeconomic 
characteristics, and urbanization-driven landscape fragmentation [7]. Olive groves and vineyards are emblematic cropping systems in the Mediterranean basin, especially in economically-marginal and peripheral rural areas. Their presence dates back to the very first stages of civilization, and their economic relevance is still an important attribute of Mediterranean landscapes, in relation to tourism development, rural economy, and environmental services [8-10]. The long cultivation history and the continuous economic exchange between the northern and the southern sides of the Mediterranean basin have determined a high-spatial variability of landscape, with crop varieties shaping agronomic and cultural traits of rural land, in turn threatened by latent socioeconomic transformations [6,11].

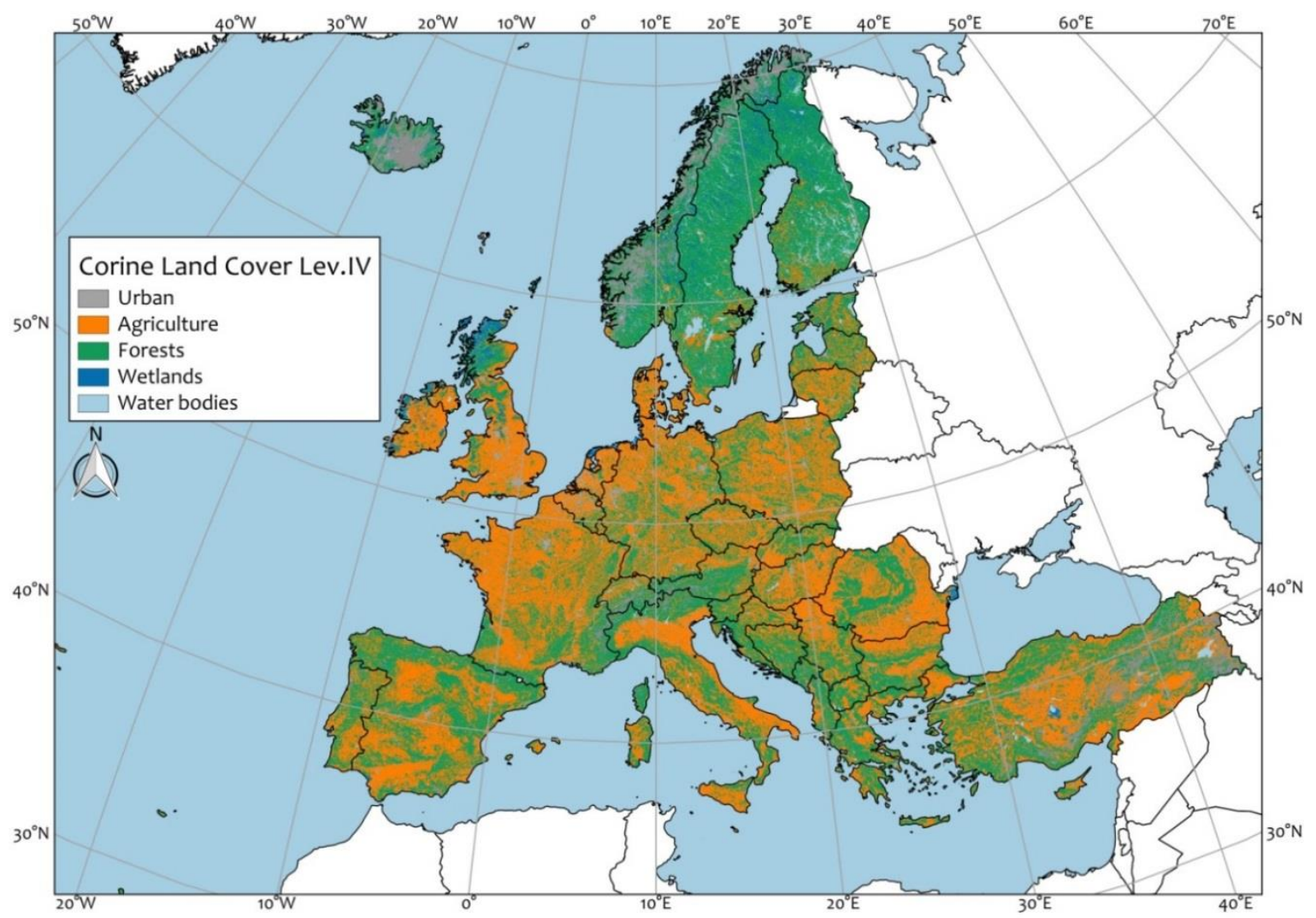

Figure 1. Agricultural and forest areas in Europe, derived from the Corine Land Cover (Level IV); urban class includes all artificial surfaces; forest areas include semi-natural green areas; source: GMES-Copernicus Land Monitoring, European Environment Agency (2012); see a complete classification in https:/ /land. copernicus.eu/eagle/files/eagle-related-projects/pt_clcconversion-to-fao-lccs3.

Olive cultivation and viticulture represent traditional (and often contrasting) cropping systems in terms of land occupation, biodiversity preservation and environmental quality. Olive cultivation is characterized by slow economic and technological changes, while viticulture entails the dynamic evolution of occupied spaces, by using crop varieties and innovative technologies [3,12-16]. In such complex agro-ecosystems, formulation of practical guidelines could prevent soil degradation, water depletion, rural area depopulation and the loss of agricultural knowledge [17,18]. When dealing with environmental resources, a sustainable approach may involve technical and scientific stakeholders [19], in order to provide a framework for promoting a sustainable food production that preserves land resources [5]. At the same time, economic sustainability has to consider production costs and the related benefits in both the short- and medium-term. For instance, cooperation between farmers and public institutions should be intensively stimulated within an integrated (economic-environmental) strategy of natural resource conservation. In these regards, environmental characterization and quality evaluation of crop productions at the farming system scale are particularly appropriate to indicate 
effective on-farm conservation measures [20]. Land resources acquire a real added value, including socioeconomic and ethical aspects, when farmers and their land (in situ and on-farm) are involved in natural resource conservation processes [21].

The present contribution discusses the environmental and socioeconomic role of (olive and vine) traditional agro-ecosystems dominating the Mediterranean landscape, advancing research ideas and planning strategies based on a multidisciplinary and highly integrated approach [20,21]. More specifically, our paper is devoted to suggest (and critically discuss) strategies (i) counteracting physical and socioeconomic degradation of rural districts devoted to olive and grapevine crops, and improving farming systems' resilience and social multi-functionality, with a specific focus on coastal areas; (ii) characterizing landscape mosaics in order to detect peculiar agro-ecosystem traits and traditional practices that better concur to enhance the agricultural production sustainability in terms of natural resource safety; and (iii) assessing the geophysical environment (including soil and water quality and agro-climatic features) of coastal areas, combining remote and proximal sensing technologies for land resource preservation. Environmental sustainability of agricultural and forest production is particularly relevant for evaluating the relationship between land resources, socioeconomic factors, and crop management strategy implementation $[15,22,23]$. In this regard, traditional agricultural systems represent reference models for sustainable land management responding to possible climate change effects. With this line of thinking, the objective of this concept note is to promote a broader discussion on sustainable land management using a multi-disciplinary approach with specific focus on Mediterranean rural landscapes, stimulating a reflection on the preservation of natural resources and socioeconomic development of traditional tree crop systems in coastal environments.

\section{Basic Concepts for a Sustainable Use of Land}

A competitive agricultural system cannot exclude the adoption of sustainable productive models preserving environmental resources. Biodiversity and landscape of non-industrial agro-ecosystems are among the environmental resources most threatened by modern production systems, and require preventive measures to counteract degradation processes. In this regard, climate change is predicted to have a major impact on small-scale farmers and marginal agro-ecosystems, with feedback effects becoming increasingly complex and place-specific [24]. In Mediterranean regions, various issues were identified as relevant factors at the base of sustainable land-use management of tree crop farming systems [25]: (i) identification of environmental degradation drivers (land-use transformations, socioeconomic forces, climate change) and (endangered) resilient tree crop systems; (ii) characterization of ecological, climatic, and physical attributes of traditional olive grove and vineyard farming systems, combining different assessment methodologies such as landscape metrics, bioclimatic indexes, remote sensing, and precision agriculture tools; (iii) mapping suitable areas for enhancing production of quality food and socioeconomic sustainability; (iv) strategic development of rapidly-adapting olive and grapevine cultivation to climate and land changes in coastal areas; and (v) formulation of practical guidelines for sustainable land resource maintenance through (direct or indirect) analysis of multifunctional (environmental and socioeconomic) value of a given cropping systems.

A comprehensive knowledge of the cause-effect relationship between soil-climate systems, agronomic practices, and agricultural production is the informative base for sustainable land management, soil protection strategies, conservation of renewable resources (including biodiversity), environmental impact reduction, promotion of agricultural yields, and high-quality products. In the Mediterranean basin, agro-ecosystems dominated by trees still provide relevant opportunities for processes of farm economic diversification [26]. Olive groves and vineyards represent the most emblematic Mediterranean cropping systems [10,27]. These species are crucial for adaptation to specific climatic, topographical and soil characters, exhibiting high plasticity, particularly for the native varieties, and optimizing the genotype-environment relationship. Many local varieties, which are biologically significant, are cultivated in both marginal agricultural areas and more open rural contests, and are at risk of biodiversity loss [28]. 
Landscape is the result of biodiversity distribution according to physiographic and structural traits [29]. Whereas agricultural landscape is the result of the interaction between natural and anthropogenic factors. The linkage between these components is particularly evident in traditional agricultural landscapes [30,31]. Different national and international protocols, like the European Landscape Convention (2000), are proposing the landscape, in all its forms, as a common good, given that agro-bio-diversity and natural resources maintain the structure and function of the landscape and human well-being [32-36]. Landscape transformations can threaten ecological functions when the suitable agricultural area is reduced, possibly leading to early processes of land degradation. Instead, olive culture and viticulture represent more traditional crop systems, which intrinsically assure biodiversity preservation and land safeguards [22]. Nevertheless, many traditional production areas for high-quality oil, grapes, and wines have been eroded because of agriculture abandonment and urbanization.

The abovementioned processes take on an increasing role of environmental degradation when coupled with global changes including climate variations, landscape transformations, population growth, and settlement sprawl in peri-urban areas [37]. Land degradation is particularly evident along the Mediterranean Sea coast due to the interaction of multiple forces [38], and requires a permanent assessment integrating field surveys, landscape analysis, remote and proximal sensing (e.g., ground-, air-, and space-based platforms), as well as statistical data analysis along with local community stakeholder interviews.

\section{Practical Actions and Innovation for Preventing Land Degradation in Traditional Rural Areas}

While experiencing global change with increasingly negative impacts on the natural environment, ecosystem balance in rural areas with traditional grape and olive production should be preserved through adequate policy strategies. New technology, such as drones, satellite imagery, ground penetrating radar (GPR) [39,40], is particularly useful in cropping systems' precision management [40,41], with the final aim to develop innovative strategies for environmental safety and market competitiveness at farm scale [2]. Additionally, novel approaches to preservation of land sustainability in agro-forest management should include the reuse of geographic provenances and varieties in the most suitable environments, known to be more adapted to local climates $[10,42,43]$. In these regards, climate strongly affects adaptive traits and the long-term co-evolution between climate and genotypes is on the basis of adaptation; at the same time, regeneration processes are much faster in agricultural land than forests. For this reason, permanent agro-climatic monitoring of rural areas devoted to olive and/or grapevines may provide an informed base to select appropriate (and low-intensive) productive choices based on variety substitution [44]. Furthermore, the maintenance of landscape structure, agro-forestry mosaic complexity, and ecological connectivity should also be considered when assessing environmental sustainability [45]. In these regards, traditional Mediterranean viticulture and olive crops, along with other relict cropping systems in economically-marginal areas, are interesting farming systems that ensure maintenance of a rich local biodiversity stock displaying high rusticity, plasticity, and multiple adaptations to both environmental and socioeconomic transformations.

An empirical framework for innovative management of grapevine and olive groves in Mediterranean vulnerable areas should be aimed at recovering and exploiting traditional landscapes contrasting together soil degradation and land abandonment $[13,46]$. Suggested actions to mitigate land degradation in these contexts include:

(i) Counteracting land degradation in olive and grapevine districts along coastal areas, with specific actions and practices for improvement of cropping system resilience and multi-functionality;

(ii) Characterizing the intimate attributes of landscape mosaics and identifying agro-ecosystem traits and traditional agronomic practices concurring to enhance agricultural production sustainability and natural resource protection; 
(iii) Assessing real-time changes in physical environments (e.g., soil and water quality, agro-climatic variables) combining remote and proximal sensing and new technologies for land resource preservation;

(iv) Improving crop production sustainability by encouraging traditional agricultural systems as reference models for landscape sustainable management, and as an effective crop model responding to climate change;

(v) Evaluating the latent relationship between land resources and socioeconomic factors, using multivariate approaches grounded on exploratory statistical techniques aimed to inform more effective strategies for sustainable crop management.

Strategic Approaches Claiming for Innovative Methodologies: A Proposal For Integrated Management Actions

Sustainable use of land resources in olive groves and vineyards of Mediterranean coastal areas is nowadays particularly demanding. Empirical analysis of traditional cropping systems are required to provide an integrated understanding of the environmental and socioeconomic values of these traditional cropping systems. The novelty of an innovative approach to crop system complexity has to be sought in the definition of their multifunctional significance, which is actually a required attribute for maintaining production competitiveness, especially in marginal areas [47]. Understanding the multiple functions of olive groves and vineyards in coastal regions could preserve their resilience to land-use changes, responding to urbanization, crop specialization or land abandonment, leading indirectly to soil and land degradation. Moreover, a comprehensive evaluation of the agro-ecosystem structure and functions represents an effective approach to the assessment of sustainable agricultural products. Characterization of the physical and socioeconomic environments will guide maintenance and restoration of natural resources, as well as crop competitiveness and land productivity through the use of new technologies such as remote and proximal sensing techniques. The provided approach will also indicate the most suitable varieties for specific contexts, promoting flexibility of production models and their restoration [4]. A better understanding of socioeconomic factors related to tree crop management in Mediterranean coastal areas will support appropriate strategy definitions providing a specific base of knowledge for spatial planners, land managers, farm-holders, local stakeholders, and more generally, interested citizens.

Characterizing olive and grapevine agro-ecosystems using proximal and remote sensing tools definitely contributes to precision strategies and management techniques against land resource depletion. In addition, it will enhance our understanding of cultural landscapes functioning, contributing to estimate the value of ecological diversity typical of such landscapes [48-51]. In the proposed logical framework, the strategic objectives mentioned above can be achieved through the following actions organized under four distinct contexts, in accordance with earlier studies [52-54]:

1. Development of an integrated and multi-disciplinary approach assessing environmental and economic sustainability of traditional agricultural systems in sensitive Mediterranean areas;

2. Identification of multiple environmental risks with an effective improvement of land-use knowledge;

3. Characterization of physiographic and ecological traits of traditional farming systems contributing to a spatial planning (e.g., land suitability) enhancing food production and socioeconomic sustainability of local districts;

4. Implementation of a specific strategy supporting rapid adaptation of olive crop and grapevine cultivations to climate change and land degradation in coastal areas.

Finally, the formulation of guidelines for sustainable maintenance of land resources may benefit from the practical knowledge and the actions proposed above, promoting the integral preservation of the multifunctional value of land (ecological, cultural and socioeconomic). 


\section{Final Remarks}

Agro-ecosystem conservation assures continuous services' provision for socioeconomic local systems. Productive systems and traditional consumption practices are increasingly faced with the (rapidly changing) environmental traits and could effectively contribute to increased stability and resilience of Mediterranean ecosystems. Recovery and conservation of agricultural resources provide positive effects and social benefits at both local and regional scales. Based on the extensive debate on traditional landscapes presented early in this note, the issue of spatial equity in natural resource distribution and environmental degradation should be more clearly addressed, especially in economically disadvantaged regions that are largely dependent on agriculture and particularly on olive and grapevine productions. In these marginal environments, climate, land-use change, and socioeconomic transformations are considered key drivers of land degradation and should be continuously monitored. Understanding multiple use and multi-functionality of tree crop landscapes, such as olive and grapevine agro-systems, will definitely contribute to preservation of rural ecosystems typical of the Mediterranean region, counteracting ecological and socioeconomic transformations that may alter natural environments and local communities.

Author Contributions: Conceptualization, L.S. and R.B.; Methodology, M.M.; Formal Analysis, C.F.; Data Curation, R.S.; Writing-Original Draft Preparation, R.B. and L.S.; Writing-Review \& Editing, R.S.; Visualization, M.M.; Supervision, M.M. and C.F.

Funding: This research received no external funding.

Acknowledgments: The Authors wish to thank Professor Gianni Quaranta and Giorgio Pontuale for their scientific and technical support.

Conflicts of Interest: The authors declare no conflicts of interest.

\section{References}

1. Colantoni, A.; Ferrara, C.; Perini, L.; Salvati, L. Assessing trends in climate aridity and vulnerability to soil degradation in Italy. Ecol. Indic. 2015, 48, 599-604. [CrossRef]

2. Duvernoy, I.; Zambon, I.; Sateriano, A.; Salvati, L. Pictures from the other side of the fringe: Urban growth and peri-urban agriculture in a post-industrial city (Toulouse, France). J. Rural Stud. 2018, 57, 25-35. [CrossRef]

3. Haberl, H.; Wackernagel, M.; Wrbka, T. Land use and sustainability indicators. An introduction. Land Use Policy 2004, 21, 193-198. [CrossRef]

4. Serra, P.; Pons, X.; Saurí, D. Land-cover and land-use change in a Mediterranean landscape: A spatial analysis of driving forces integrating biophysical and human factors. Appl. Geogr. 2008, 28, 189-209. [CrossRef]

5. Corona, P.; Cutini, A.; Chiavetta, U.; Paoletti, E. Forest-food nexus: A topical opportunity for human well-being and silviculture. Ann. Silvic. Res. 2016, 40, 1-10.

6. Salvati, L.; Petitta, M.; Ceccarelli, T.; Perini, L.; Di Battista, F.; Scarascia, M.E.V. Italy's renewable water resources as estimated on the basis of the monthly water balance. Irrig. Drain. 2008, 57, 507-515. [CrossRef]

7. Scarascia-Mugnozza, G.; Oswald, H. Forests of the Mediterranean region: Gaps in knowledge and research needs. For. Ecol. Manag. 2000, 132, 97-109. [CrossRef]

8. Cohen, M.; Bilodeau, C.; Alexandre, F.; Godron, M.; Andrieu, J.; Gresillon, E.; Garlatti, F.; Morganti, A. What is the plant biodiversity in a cultural landscape? A comparative, multi-scale and interdisciplinary study in olive groves and vineyards (Mediterranean France). Agric. Ecosyst. Environ. 2015, 212, 175-186. [CrossRef]

9. Ferrara, A.; Salvati, L.; Sabbi, A.; Colantoni, A. Soil resources, land cover changes and rural areas: Towards a spatial mismatch? Sci. Total Environ. 2014, 478, 116-122. [CrossRef] [PubMed]

10. Loumou, A.; Giourga, C. Olive groves: "The life and identity of the Mediterranean". Agric. Hum. Values 2003, 20, 87-95. [CrossRef]

11. Ferrara, A.; Salvati, L.; Sateriano, A.; Carlucci, M.; Gitas, I.; Biasi, R. Unraveling the "stable" landscape: A multi-factor analysis of unchanged agricultural and forest land (1987-2007) in a rapidly-expanding urban region. Urban Ecosyst. 2016, 19, 835-848. [CrossRef] 
12. Agnoletti, M.; Cargnello, G.; Gardin, L.; Santoro, A.; Bazzoffi, P.; Sansone, L.; Pezza, L.; Belfiore, N. Traditional landscape and rural development: Comparative study in three terraced areas in northern, central and southern Italy to evaluate the efficacy of GAEC standard 4.4 of cross compliance. Ital. J. Agron. 2011, 6, 121-139. [CrossRef]

13. Sabbi, A.; Salvati, L. Searching for a downward spiral? Soil erosion risk, agro-forest landscape and socioeconomic conditions in Italian local communities. Land Use Policy 2014, 41, 388-396. [CrossRef]

14. Salvati, L.; Tombolini, I. A Diachronic Classification of Peri-urban Forest Land Based on Vulnerability to Desertification. Int. J. Environ. Res. 2014, 8, 279-284.

15. Pili, S.; Grigoriadis, E.; Carlucci, M.; Clemente, M.; Salvati, L. Towards sustainable growth? A multi-criteria assessment of (changing) urban forms. Ecol. Indic. 2017, 76, 71-80. [CrossRef]

16. Karamesouti, M.; Detsis, V.; Kounalaki, A.; Vasiliou, P.; Salvati, L.; Kosmas, C. Land-use and land degradation processes affecting soil resources: Evidence from a traditional Mediterranean cropland (Greece). Catena 2015, 132, 45-55. [CrossRef]

17. Salvati, L. The spatial pattern of soil sealing along the urban-rural gradient in a Mediterranean region. J. Environ. Plan. Manag. 2013, 57, 848-861. [CrossRef]

18. Zitti, M.; Ferrara, C.; Perini, L.; Carlucci, M.; Salvati, L. Long-Term Urban Growth and Land Use Efficiency in Southern Europe: Implications for Sustainable Land Management. Sustainability 2015, 7, 3359-3385. [CrossRef]

19. Grilli, G.; Nikodinoska, N.; Paletto, A.; De Meo, I. Stakeholders' preferences and economic value of forest ecosystem services: An example in the Italian alps. Balt. For. 2015, 21, 298-307.

20. Lorenz, M. International co-operative programme on assessment and monitoring of air pollution effects on forests-ICP Forests. Water Air Soil Pollut. 1995, 85, 1221-1226. [CrossRef]

21. Biasi, R.; Brunori, E. The on-farm conservation of grapevine (Vitis vinifera L.) landraces assures the habitat diversity in the viticultural agro-ecosystem. VITIS J. Grapevine Res. 2015, 54, 265-269.

22. Brunori, E.; Farina, R.; Biasi, R. Sustainable viticulture: The carbon-sink function of the vineyard agro-ecosystem. Agric. Ecosyst. Environ. 2016, 223, 10-21. [CrossRef]

23. Ruddell, S.; Sampson, R.; Smith, M.; Giffen, R.; Cathcart, J.; Hagan, J.; Sosland, D.; Godbee, J.; Heissenbuttel, J.; Lovett, S.; et al. The role for sustainably managed forests in climate change mitigation. J. For. 2007, 105, 314-319.

24. Bellon, M.R.; Hodson, D.; Hellin, J. Assessing the vulnerability of traditional maize seed systems in Mexico to climate change. Proc. Natl. Acad. Sci. USA 2011, 108, 13432-13437. [CrossRef] [PubMed]

25. Morton, J.F. The impact of climate change on smallholder and subsistence agriculture. Proc. Natl. Acad. Sci. USA 2007, 104, 19680-19685. [CrossRef] [PubMed]

26. Achtak, H.; Ater, M.; Oukabli, A.; Santoni, S.; Kjellberg, F.; Khadari, B. Traditional agroecosystems as conservatories and incubators of cultivated plant varietal diversity: The case of fig (Ficus carica L.) in Morocco. BMC Plant Biol. 2010, 10, 28. [CrossRef] [PubMed]

27. Aretano, R.; Petrosillo, I.; Zaccarelli, N.; Semeraro, T.; Zurlini, G. People perception of landscape change effects on ecosystem services in small Mediterranean islands: A combination of subjective and objective assessments. Landsc. Urban Plan. 2013, 112, 63-73. [CrossRef]

28. Biasi, R.; Brunori, E.; Smiraglia, D.; Salvati, L. Linking traditional tree-crop landscapes and agro-biodiversity in central Italy using a database of typical and traditional products: A multiple risk assessment through a data mining analysis. Biodivers. Conserv. 2015, 24, 3009-3031. [CrossRef]

29. González, A.; Fry, J. Developing Integrated Biodiersity Impact Assessment (IBIA): Data limitations on GIS support. In Proceedings of the IAIA11 Conference Proceedings, Puebla, Mexico, 28 May-4 June 2011; pp. 1-7.

30. Antrop, M. Why landscapes of the past are important for the future. Landsc. Urban Plan. 2005, 70, 21-34. [CrossRef]

31. Zimmermann, R.C. Recording rural landscapes and their cultural associations: Some initial results and impressions. Environ. Sci. Policy 2006, 9, 360-369. [CrossRef]

32. Farina, A. The Cultural Landscape as a Model for the Integration of Ecology and Economics. Bioscience 2000, 50, 313-320. [CrossRef]

33. Marchetti, M.; Vizzarri, M.; Lasserre, B.; Sallustio, L.; Tavone, A. Natural capital and bioeconomy: Challenges and opportunities for forestry. Ann. Silvic. Res. 2014, 38, 62-73. 
34. Paetzold, A.; Warren, P.H.; Maltby, L.L. A framework for assessing ecological quality based on ecosystem services. Ecol. Complex. 2010, 7, 273-281. [CrossRef]

35. Marchi, M.; Paletto, A.; Cantiani, P.; Bianchetto, E.; De Meo, I. Comparing Thinning System Effects on Ecosystem Services Provision in Artificial Black Pine (Pinus nigra J. F. Arnold). Forests 2018, 9, 188. [CrossRef]

36. Raudsepp-Hearne, C.; Peterson, G.D.; Bennett, E.M. Ecosystem service bundles for analyzing tradeoffs in diverse landscapes. Proc. Natl. Acad. Sci. USA 2010, 107, 5242-5247. [CrossRef] [PubMed]

37. Munafò, M.; Salvati, L.; Zitti, M. Estimating soil sealing at country scale-Italy as a case study. Ecol. Indic. 2013, 26, 36-43. [CrossRef]

38. Salvati, L.; Zitti, M.; Ceccarelli, T. Integrating economic and environmental indicators in the assessment of desertification risk: A case study. Appl. Ecol. Environ. Res. 2008, 6, 129-138. [CrossRef]

39. Allred, B.J.; Daniels, J.J.; Ehsani, M.R. Agricultural Geophysics. Water 2008, xxii, 410-418.

40. Salvati, L. Urban expansion and high-quality soil consumption-an inevitable spiral? Cities 2013, 31, 349-356. [CrossRef]

41. Schieffer, J.; Dillon, C. The economic and environmental impacts of precision agriculture and interactions with agro-environmental policy. Precis. Agric. 2014, 16, 46-61. [CrossRef]

42. Siuli Roy, A.D.; Bandyopadhyay, S. Agro-sense: Precision agriculture using sensor-based wireless mesh networks. In Proceedings of the International Telecommunication Union-Proceedings of the 1st ITU-T Kaleidoscope Academic Conference, Innovations in NGN, K-INGN, Geneva, Switzerland, 12-13 May 2008.

43. Varma, V.K.; Ferguson, I.; Wild, I. Decision support system for the sustainable forest management. For. Ecol. Manag. 2000, 128, 49-55. [CrossRef]

44. Marchi, M.; Ducci, F. Some refinements on species distribution modelling using tree-level National Forest Inventories for supporting forest management and marginal forest population detection. iForest 2018, 11, 291-299. [CrossRef]

45. Jones, G.V. Climate and Terroir: Impacts of Climate Variability and Change on Wine. Geosci. Can. 2003, 12, $1-14$.

46. Cullotta, S.; Barbera, G. Mapping traditional cultural landscapes in the Mediterranean area using a combined multidisciplinary approach: Method and application to Mount Etna (Sicily; Italy). Landsc. Urban Plan. 2011, 100, 98-108. [CrossRef]

47. Boardman, J.; Poesen, J.; Evans, R. Socio-economic factors in soil erosion and conservation. Environ. Sci. Policy 2003, 6, 1-6. [CrossRef]

48. Salvati, L.; Carlucci, M. The economic and environmental performances of rural districts in Italy: Are competitiveness and sustainability compatible targets? Ecol. Econ. 2011, 70, 2446-2453. [CrossRef]

49. Cimini, D.; Tomao, A.; Mattioli, W.; Barbati, A.; Corona, P. Assessing impact of forest cover change dynamics on high nature value farmland in Mediterranean mountain landscape. Ann. Silvic. Res. 2013, 37, $29-37$.

50. Meeus, J.H.A.; Wijermans, M.P.; Vroom, M.J. Agricultural landscapes in Europe and their transformation. Landsc. Urban Plan. 1990, 18, 289-352. [CrossRef]

51. Salvati, L.; Gargiulo, V.; Rontos, K.; Sabbi, A. Latent Exurban Development: City Expansion along the Rural-To-Urban Gradient in Growing and Declining Regions of Southern Europe. Urban Geogr. 2013, 34, 376-394. [CrossRef]

52. Bajocco, S.; De Angelis, A.; Salvati, L. A satellite-based green index as a proxy for vegetation cover quality in a Mediterranean region. Ecol. Indic. 2012, 23, 578-587. [CrossRef]

53. Salvati, L.; Zitti, M.; Perini, L. Fifty years on: Long-term patterns of land sensitivity to desertification in Italy. Land Degrad. Dev. 2016, 27, 97-107. [CrossRef]

54. Kosmas, C.; Karamesouti, M.; Kounalaki, K.; Detsis, V.; Vassiliou, P.; Salvati, L. Land degradation and long-term changes in agro-pastoral systems: An empirical analysis of ecological resilience in Asteroussia-Crete (Greece). Catena 2016, 147, 196-204. [CrossRef]

(C) 2018 by the authors. Licensee MDPI, Basel, Switzerland. This article is an open access article distributed under the terms and conditions of the Creative Commons Attribution (CC BY) license (http:/ / creativecommons.org/licenses/by/4.0/). 